\title{
Neuromielitis óptica: a propósito de un caso
}

\author{
Neuromyelitis optica: a case report
}

Neuromielite óptica: a propósito de um caso

\author{
Flor de María Elisa Del Carpio Medina ${ }^{1 a}$ \\ Diego José Mamani Maquera ${ }^{1 b}$ \\ Gerson Saúl Mita Ticona ${ }^{1 b}$
}

\section{Resumen}

La neuromielitis óptica (NMO) o enfermedad de Devic, definida anteriormente por la ocurrencia de neuritis óptica (NO) y mielitis transversa (MT), se considera, actualmente, como un espectro de desórdenes autoinmunes, inflamatorios y desmielinizantes del SNC. Caso clínico: Paciente con cuadro clínico de 2 semanas de evolución, caracterizado por disminución abrupta de la agudeza visual en ambos ojos, no asociada a dolor, concomitantemente presenta disminución de la sensibilidad en región abdominal y disminución de la fuerza muscular en ambos miembros inferiores, que imposibilitan la deambulación. Resultados: El descubrimiento del autoanticuerpo AQP4 (anti-AQP4) y su asociación con la NMO, así como diferencias en presentación clínica, laboratorio, neuroimágenes, respuesta a tratamiento y pronóstico, han permitido diferenciar esta patología de la esclerosis múltiple (EM). Conclusión: El pronóstico de los pacientes con NMO es desalentador, desde la incapacidad para caminar sin ayuda, hasta la ceguera unilateral o bilateral, pueden presentarse en el $50 \%$ de los casos.

Palabras clave: neuromielitis óptica, neuritis óptica, mielitis transversa, aquoporina-4

\section{Abstract}

The neuromyelitis optica (NMO) or Devic's disease, previously defined by the occurrence of optical neuritis (NO) and transverse myelitis (MT), is currently considered as a spectrum of autoimmune, inflammatory and demyelinating disorders of the CNS. Clinical case: Patient with 2-week clinical history, characterized by abrupt decrease in visual acuity in both eyes, not associated with pain, concomitantly presents decreased sensitivity in the abdominal region and decreased muscle strength in both lower limbs, which make walking impossible. Results: The discovery of the AQP4 autoantibody (anti-AQP4) and its association with NMO, as well as differences in clinical presentation, laboratory, neuroimaging, response to treatment and prognosis, have allowed differentiating this pathology from multiple sclerosis (MS). Conclusion: The prognosis of patients with NMO is discouraging, from the inability to walk unaided, to unilateral or bilateral blindness, can occur in $50 \%$ of cases.

Keywords: optic neuromyelitis, optic neuritis, transverse myelitis, aquoporin-4

\footnotetext{
${ }^{1}$ Hospital Nacional Carlos Alberto Seguín Escobedo-EsSalud. Arequipa, Perú

${ }^{a}$ Médico asistente del Servicio de Oftalmología

${ }^{\mathrm{b}}$ Médico residente del Servicio de Oftalmología
} 


\section{Resumo}

A Neuromielite óptica (NMO) ou doença de Devic, definida anteriormente pela ocorrência de neurite óptica (NO) e mielite transversal (MT), é atualmente considerada como um espectro de desordens auto-imunes, inflamatórias e desmielinizantes do SNC. Caso clínico: Paciente com quadro clínico de 2 semanas de evolução, caracterizado por diminuição abrupta da acuidade visual em ambos os olhos, não associada a dor, concomitantemente apresenta diminuição da sensibilidade na região abdominal e diminuição da força muscular em ambos os membros inferiores, que impossibilitam a deambulação. Resultados: A descoberta do auto-anticorpo AQP4 (anti-AQP4) e sua associação com a NMO, bem como diferenças em apresentação clínica, laboratório, neuroimagens, resposta ao tratamento e prognóstico, permitiram diferenciar esta patologia da esclerose múltipla (EM). Conclusão: O prognóstico dos pacientes com NMO é desencorajador, desde a incapacidade de caminhar sem ajuda, até à cegueira unilateral ou bilateral, podem apresentar-se em $50 \%$ dos casos.

Palavras-chave: neuromielite óptica, neurite óptica, mielite transversa, aquoporina-4

\section{Introducción}

La neuromielitis óptica (NMO) es una enfermedad desmielinizante, autoinmune e inflamatoria crónica del sistema nervioso central (SNC) caracterizada por afectar severamente la médula espinal y los nervios ópticos de forma monofásica o en brotes y remisiones, siendo una causa de discapacidad en jóvenes y adultos. ${ }^{1}$

La primera descripción fue realizada por Sir Clifford Albutt en 1870, pero Eugene Devic y Fernand Gault fueron quienes, en 1894, caracterizaron tanto la clínica como los procesos patológicos de esta entidad cuando publicaron los casos de 17 pacientes con asociación de neuritis óptica (NO) y mielitis transversa (MT) en forma simultánea o separadas por escaso tiempo. La edad media de inicio es de 40 años, puede presentarse en población pediátrica y en ancianos, y es 9 veces más frecuente en mujeres que en hombres. ${ }^{1,2}$

La relación entre la NMO y la EM se ha debatido durante mucho tiempo, pero después del descubrimiento del autoanticuerpo específico en sangre llamado IgG-NMO o antiAQP4, que se une a los canales de agua diseminados en el SNC, Ilamados acuaporina-4 (AQP4), numerosos informes han aclarado que la NMO tiene clínica, resonancia magnética, laboratorio y características inmunopatológicas distintas de la EM. ${ }^{2}$
Los criterios diagnósticos para la NMO se han revisado varias veces, y el autoanticuerpo AQP4 definitivamente ha jugado un papel fundamental en la evolución del diagnóstico de la NMO. Como los síndromes cerebrales también ocurren en la $\mathrm{NMO}$, el término de trastorno del espectro de la NMO fue propuesto en el consenso internacional de criterios de diagnóstico en 2015, para cubrir todo el espectro clínico. ${ }^{2}$

La presentación clínica consiste en neuritis óptica o mielitis aguda transversa, cuya recuperación suele ser escasa o nula. Las técnicas de imagen muestran frecuentemente lesiones medulares longitudinales y extensas que abarcan 3 o más segmentos vertebrales. Es de vital importancia el diagnóstico diferencial inicial con la EM y otros trastornos autoinmunes dado que el tratamiento de muchos de estos padecimientos puede agravar la NMO., ${ }^{1,3}$

\section{Caso clínico}

Paciente mujer de 56 años, natural y procedente de Puno, quien presenta un cuadro clínico de 2 semanas de evolución, caracterizado por disminución abrupta de la agudeza visual en OD, no asociada a dolor, y una semana después presentó disminución abrupta de la agudeza visual en OI, no asociada a dolor; concomitantemente presenta disminución de la sensibilidad en región 
abdominal y disminución de la fuerza muscular en ambos miembros inferiores, que imposibilitan la deambulación.

Al examen físico, la paciente se encuentra despierta, orientada en las 3 esferas, lenguaje claro, fuerza muscular en miembros superiores conservada, en miembro inferior derecho hay un esbozo de movimiento que no vence la gravedad (1/5), en miembro inferior izquierdo hay movimiento amplio en contra de una fuerza manual moderada (4/5), hiperreflexia en miembros inferiores, Babinsky (+) bilateral y pérdida de reflejos abdominocutáneos.

Agudeza visual: OD: no percepción de luz, OI: movimiento de manos; PIO: OD: 12 y OI: 12; balance muscular: no limitación de ducciones, no dolor a la motilidad ocular externa en ambos ojos; fenómeno de Bell: presente en ambos ojos; pupilas: OD: Midriática de $5 \mathrm{~mm}$, DPA $(+/++++)$ y Ol: Midriática de $4 \mathrm{~mm}$, DPA(-). Segmento anterior: OD: Conjuntiva normocrómica, córnea clara, cámara anterior formada sin células, opacidad de cristalino N2 C2. Ol: conjuntiva normocrómica, córnea clara, cámara anterior formada sin células, opacidad de cristalino N1 C2. Fondo de ojo: OD: papila pálida en región temporal, con bordes irregulares y no bien definidos, brillo macular conservado, retina periférica sin alteraciones. OI: papila anaranjada, RCD: 0,4 con bordes regulares y bien definidos, con emergencia de vasos centrales sin alteraciones, brillo macular conservado, retina periférica sin alteraciones (Figura 1).

\section{Figura 1}

Nervio óptico derecho con palidez en región temporal y nervio óptico izquierdo de características normales

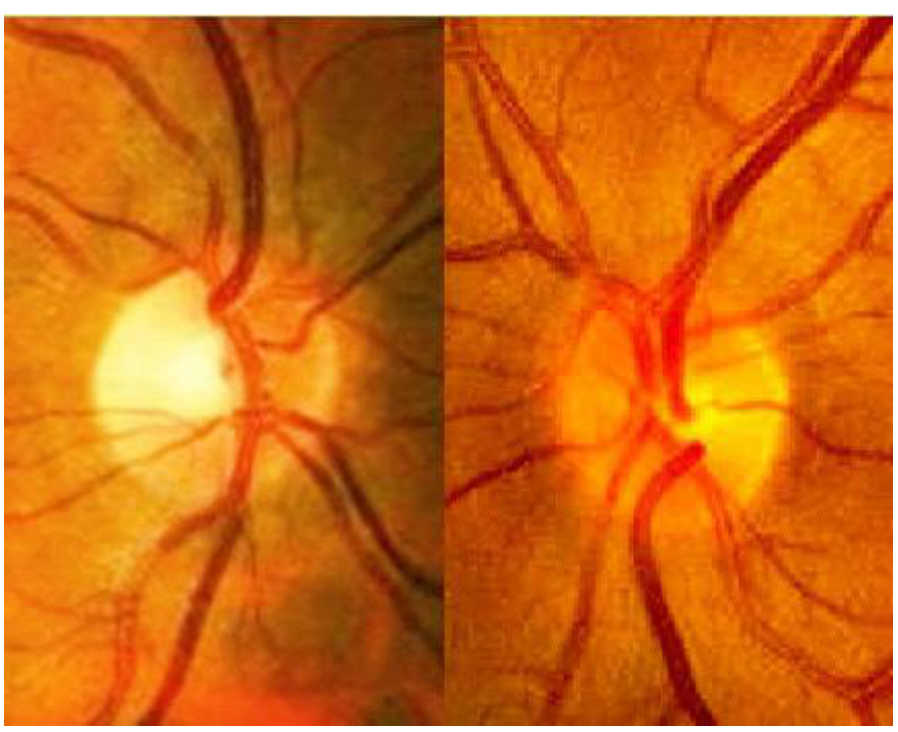

La RMN cerebral resulto normal. Se realizó una RMN en corte axial a nivel de órbitas; en secuencia T2 STIR se evidenció un engrosamiento y lesión hiperintensa en el nervio óptico derecho (Figura 2) y en secuencia T1 FSE se evidenció un realce focal con el contraste a nivel del nervio óptico izquierdo (Figura 3). 


\section{Figura 2}

Imagen de RMN en secuencia T2-STIR en corte axial a nivel de órbitas: engrosamiento y lesión hiperintensa en nervio óptico derecho

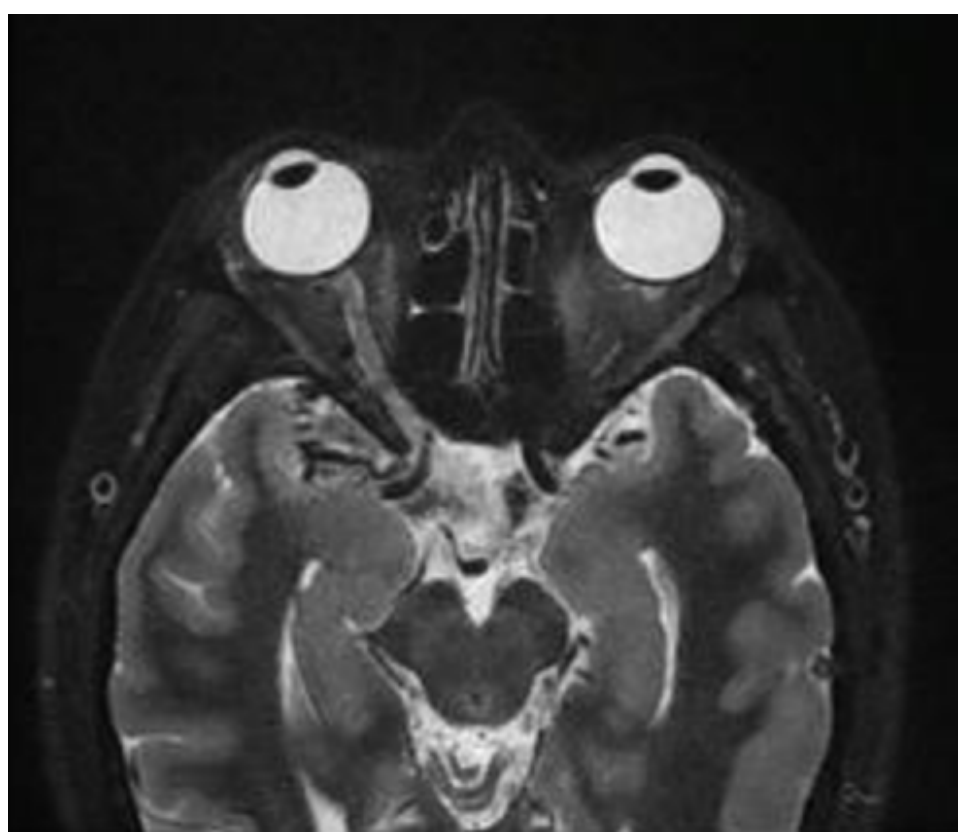

\section{Figura 3}

Imagen de RMN en secuencia T1-FSE en corte axial a nivel de órbitas: realce focal con el contraste a nivel del nervio óptico izquierdo

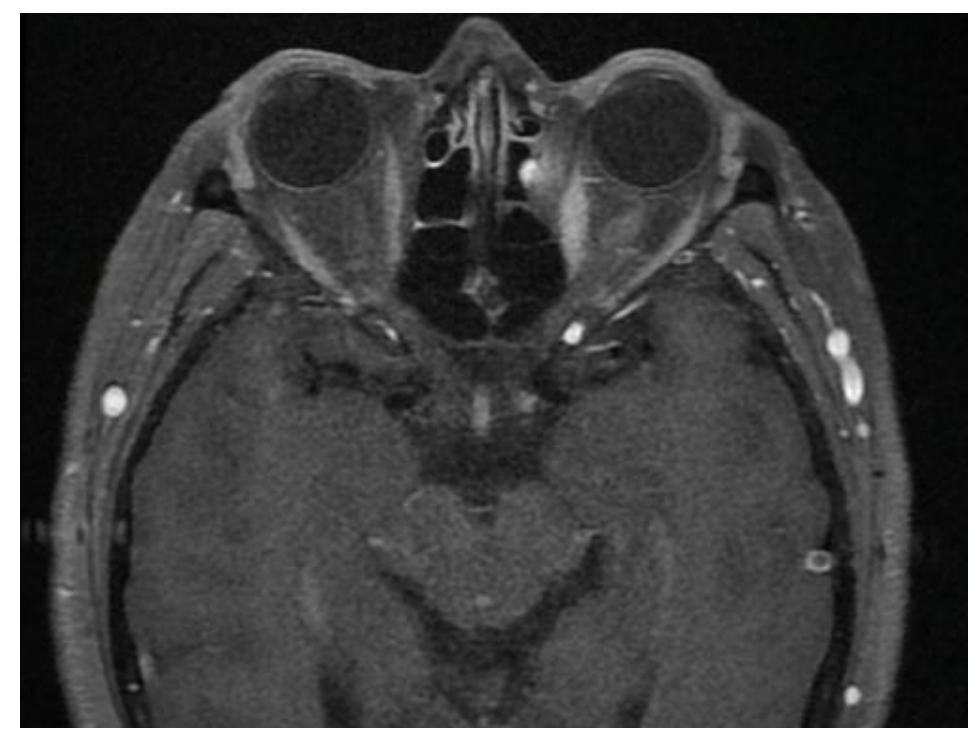

Se realizó una RMN de región cérvico-torácica en corte sagital, en secuencia T2-FSE evidenció una lesión hiperintensa extensa que va desde C2 a C6 y otra que va desde D5 a D8 (Figura 4). 


\section{Figura 4}

Imagen de RMN en secuencia T2-FSE en corte sagital a nivel de columna cérvico-toráccica: lesión hiperintensa que va desde $C 2$ a C6 y otra que va desde D5 a D8

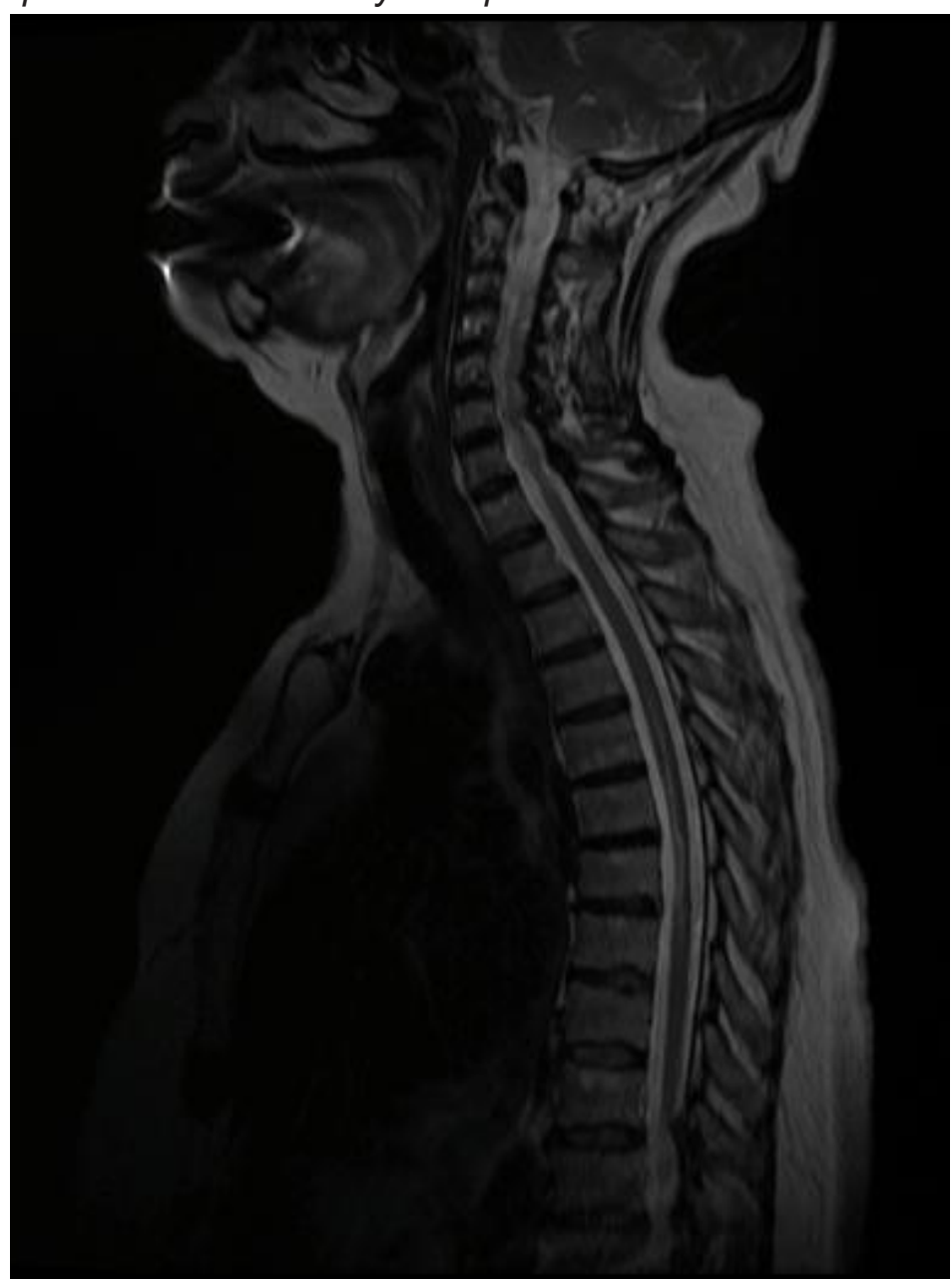

Durante su ingreso la analítica sanguínea resultó normal, ANA (-), p-ANCA (-), c-ANCA (-), el estudio del líquido cefalorraquídeo reveló una moderada pleocitosis. Se realizó estudio del autoanticuerpo acuoporina-4 (anti-AQP4), el cual resultó positivo.

El diagnóstico definitivo de neuromielitis óptica se confirmó después de que se excluyó la enfermedad autoinmune sistémica, evidencia de mielitis aguda y neuropatía óptica; las imágenes por resonancia magnética de la médula espinal mostraron anomalía que se extendía más allá de tres segmentos vertebrales, y resultados positivos de antiAQP4 en suero.
La paciente fue hospitalizada y tratada inicialmente con Metilprednisolona a dosis de 1 g/día EV y Azatioprina a dosis de 100 mg/día VO sin presentar mejoría clínica, por lo que el tratamiento fue cambiado por un anticuerpo monoclonal (Rituximab) semanas después, mostrando mejoría clínica respecto a la fuerza y sensibilidad en miembros inferiores. No hubo mejoría de la agudeza visual, hasta 2 meses después de la primera evaluación realizada por el Servicio de Oftalmología.

\section{Discusión}

Del 80 al $90 \%$ de los trastornos del espectro de la neuromielitis óptica seropositivos para anti-AQP4 son formas recurrentes con importante grado de 
discapacidad en cada evento. Las recaídas pueden ocurrir dentro del primer año (60\%) o primeros 3 años (90\%), recomendando un período libre de 5 años para establecer si cumple criterios de forma monofásica. ${ }^{4}$

Los trastornos del espectro neuromielitis óptica son un grupo de trastornos inflamatorios del SNC que se caracterizan por episodios de desmielinización y daño axonal mediada por el sistema inmunitario (anti-AQP4) que involucran principalmente los nervios ópticos y la médula espinal. ${ }^{4,5}$

Pueden presentarse variantes clínicas, que incluyen formas limitadas (neuritis o mielitis aislada), síndromes de afección del tallo cerebral, síndromes diencefálicos agudos, mielitis longitudinalmente extensa asociada a enfermedades autoinmunes y neuritis óptica. ${ }^{5}$

La NMO continúa siendo una enfermedad incurable. El objetivo del tratamiento es el control de los síntomas agudos, la prevención médica de las complicaciones y la rehabilitación. ${ }^{6}$

En muchos casos, el pronóstico de la enfermedad es nefasto. Las recaídas ocurren frecuentemente dentro de los primeros tres a cinco años tras el inicio de la enfermedad; y más del $50 \%$ de los pacientes quedan con incapacidad para caminar y ciegos de uno o ambos ojos, a causa de la NMO, tal como ocurrió en el presente caso. ${ }^{7}$

\section{Referencias}

1. Carnero E, Leguizamón F, Colla P, Alonso R. Neuromielitis óptica: actualización clínica y terapéutica. Neurol Arg. 2013; 5(4):259-269.

2. Fujihara K. Neuromyelitis optica spectrum disorders: still evolving and broadening. Curr Opin Neur. 2019; 32(3):385-394.

3. Evangelopoulos M, Andreadou E, Koutsis G, Koutoulidis V, Anagnostouli M, Katsika P. Treatment of Neuromyelitis optica and Neuromyelitis Optica Spectrum Disorders with Rituximab using a maintenance treatment régimen and close CD19 B cells monitoring. A six years follow-up. Jour of the Neur Scien. 2016; 372:92-96.

4. Kim H, Paul F, Lana-Peixoto. MRI characteristics of neuromyelitis optica spectrum disorder: an international update. Neur. 2015; 84:1165-1173.

5. Zhu R, Liu X, He Z. Widely spread corticospinal tracts lesions in a case of neuromyelitis optica. Clin Neurol Neurosurg. 2017; 161:56-58.

6. Jarius S, Wildemann B, Paul F. Neuromyelitis optica: clinical features, immunopathogenesis and treatment. Clin Exp Immunol. 2014; 176(2):149-164.

7. Chiquete E, Navarro J, Ayala R, Gutiérrez $\mathrm{N}$, Solórzano A. Neuromielitis óptica: actualización clínica. Rev Neurol. 2010; 51(5):289-94.

\section{Correspondencia:}

md.diegojose@gmail.com
Fecha de recepción: 26/11/2020

Fecha de aceptación: 29/01/2021 